\title{
Characterization of Early Leaf Spot Suppression by Strip Tillage in Peanut
}

\author{
E. G. Cantonwine, A. K. Culbreath, and K. L. Stevenson
}

First author: former graduate student, second author: professor, and third author: associate professor, Department of Plant Pathology, The University of Georgia Coastal Plain Experiment Station, Tifton 31793-0748.

Accepted for publication 31 August 2006.

\begin{abstract}
Cantonwine, E. G., Culbreath, A. K., and Stevenson, K. L. 2007. Characterization of early leaf spot suppression by strip tillage in peanut. Phytopathology 97:187-194.

Epidemics of early leaf spot of peanut (Arachis hypogaea), caused by Cercospora arachidicola, are less severe in strip-tilled than conventionally tilled fields. Experiments were carried out to characterize the effect of strip tillage on early leaf spot epidemics and identify the primary target of suppression using a comparative epidemiology approach. Leaf spot intensity was assessed weekly as percent incidence or with the Florida 1-to-10 severity scale in peanut plots that were conventionally or strip tilled. The logistic model, fit to disease progress data, was used to

assessed independently. For experiments combined, estimated $\mathrm{y}_{0}$ was less in strip-tilled than conventionally tilled plots, and $\mathrm{r}$ was comparable. The epidemic was delayed in strip-tilled plots by an average of 5.7 and 11.7 days based on incidence and severity, respectively. Tillage did not consistently affect mean canopy temperature, relative humidity, or frequency of environmental records favorable for infection or spore dispersal. Host response to infection was not affected by tillage, but infections were detected earlier and at higher frequencies with noninoculated detached leaves from conventionally tilled plots. These data suggest that strip tillage delays early leaf spot epidemics due to fewer initial infections; most likely a consequence of less inoculum being dispersed to peanut leaves from overwintering stroma in the soil.
\end{abstract} estimate initial disease $\left(\mathrm{y}_{0}\right)$ and epidemic rate $(\mathrm{r})$ parameters. Environmental variables, inoculum abundance, and field host resistance were
Additional keyword: modeling.
Disease development requires the presence of a virulent pathogen, a susceptible host, and an environment conducive for infection. The interaction of these factors explains variation in the amount of disease in a population, as modeled conceptually by the disease triangle (1). Agronomic practices can affect all three components of the disease triangle. The targeted components of some practices are obvious, such as reducing host susceptibility by planting a resistant cultivar; however, impacts of other practices are not always clear. Conventional tillage with a moldboard plow, once considered essential for managing soilborne pathogens, has been shown to have variable effects on disease epidemics $(4,5,9,17)$.

Epidemics can be suppressed by reducing the amount or effectiveness of initial inoculum or disease $\left(\mathrm{y}_{0}\right)$, reducing the rate of disease increase $(r)$, or reducing the duration of the epidemic $(t)$. Delayed epidemic development is most often associated with a reduction in the amount of initial inoculum or disease, whereas reduced epidemic rates typically are due to fewer secondary infections (6). Quantitative modeling and comparison of disease progress curves can help assess whether disease suppression is the result of a reduction in initial inoculum or disease, or a reduction in the rate of epidemic increase (12).

Early leaf spot of peanut (Arachis hypogaea L.) is caused by Cercospora arachidicola S. Hori, (teleomorph = Mycosphaerella arachidis Deighton). Infections of $C$. arachidicola result in lesions on leaves, petioles, and stems that often lead to premature defoliation, loss of integrity of the geocarpophore, or peg, and yield loss (20). This pathogen is a hemibiotroph of peanut with no known alternative host (23). The fungus overwinters as stroma or

Corresponding author: A. K. Culbreath; Email address: spotwilt@uga.edu

DOI: 10.1094/PHYTO-97-2-0187

(c) 2007 The American Phytopathological Society mycelium on crop residue in the soil, to which initial inoculum most often is attributed (20). Primary infections usually occur on the adaxial surface of lower leaves, after a period of rain or continuous leaf wetness (21). Incubation and latent periods vary by peanut cultivar and environment, and can be as short as 9 and 18 days, respectively $(3,10,19)$. Secondary inoculum is produced on mature lesions after periods of extended leaf wetness and temperatures $>19^{\circ} \mathrm{C}(20)$. Spores are released from lesions in greatest densities between sunrise and early afternoon (2). Spore dispersal agents include rain splash, wind, and insects (20). Initial infections typically begin after plants begin to bloom, $\approx 30$ days after planting (DAP), because peanut shows some resistance to leaf spot pathogens during the vegetative phase (15). Symptoms typically appear first in the lower canopy and then in the upper canopy as the epidemic progresses. Complete defoliation of susceptible cultivars is common when fungicides are not used.

Epidemics of early leaf spot have been reported to be more severe in conventionally tilled than strip-tilled or no-tilled fields $(16,17)$, with suppression in strip-tilled fields equivalent to that provided by three to five applications of chlorothalonil $(7,16)$. The mechanism of suppression by strip tillage is not known. Strip tillage may provide a less favorable microclimate for spore production or infection, enhance host resistance, or reduce pathogen survival, dispersal, or virulence. Visual comparisons of disease progress curves, based on Florida 1-to-10 scale ratings, suggest that strip tillage causes a delay in the epidemic development rather than a reduction in the rate of epidemic progress (16). Unfortunately, the Florida scale may not be appropriate for model comparisons because ratings are more subjective when disease levels are low, and the scale is not proportional to disease incidence or severity (8). However, models based on disease incidence alone often are not sufficient for description of the entire epidemic because incidence can reach $100 \%$ well before the crop is harvested. The objectives of this study were to characterize disease 
suppression by strip tillage and to identify the primary target of suppression using a comparative epidemiology approach.

\section{MATERIALS AND METHODS}

Experimental design. Field studies were conducted at the University of Georgia Coastal Plain Experiment Station, Tifton, in 2002 to 2004. Soil type was a Tifton loamy sand. Fields were planted to cotton (Gossypium hirsutum L.) the previous year, and peanut 2 years prior, each under conventional tillage. Winter wheat (Triticum aestivum) was planted as a cover crop the previous fall. Conventional and strip-tillage treatments were randomized over three plots (replications) at the Rigdon Farm in 2002 and 2003, four replications at the Blackshank Farm in 2003, and four replications at the Rigdon and Blackshank Farms in 2004. Plots were planted to the susceptible cv. Georgia Green unless otherwise stated, and no fungicides were applied.

Conventionally tilled plots were mowed and disked twice before the soil was deep turned with a switch plow, 20 to $25 \mathrm{~cm}$ deep, and bedded with a disk bedder. Ethalfluralin (Sonolan HFP 3.0; Dow AgroScience LLC, Indianapolis, IN) at $0.95 \mathrm{~kg}$ a.i ha ${ }^{-1}$ and S-metoalochlor (Dual Magnum 8E; Syngenta Crop Protection, Greensboro, NC) at $1.68 \mathrm{~kg}$ a.i. ha ${ }^{-1}$ were incorporated into the tilled beds. In the strip-tilled plots, the cover crop was killed with glyphosate (Roundup 4 EC; Monsanto, Kansas City, MO) at $1.2 \mathrm{~kg}$ a.i. $\mathrm{ha}^{-1}$. A subsoil shank attached to a strip-till implement (Kelley Manufacturing Co., Tifton, GA) loosened the plow pan $33 \mathrm{~cm}$ beneath the row, while the implement tilled strips $\approx 20$ to $25 \mathrm{~cm}$ wide. Tillage plot sizes varied for each experiment but exceeded 10.8 by $39.9 \mathrm{~m}$ in all cases. Treatment plot size was 1.8 by 6.0 to $7.5 \mathrm{~m}$. Planting dates were 17 May 2002, 20 May at the Rigdon Farm and 15 May at the Blackshank Farm in 2003, and 25 May at the Rigdon Farm and 26 May at the Blackshank Farm in 2004.

Disease assessments. Early leaf spot incidence was assessed weekly, beginning when disease was first noticed. Disease incidence (the percentage of leaves with one or more lesions or defoliated leaflets) was assessed on leaves of 10 lateral branches arbitrarily collected from each plot, with the exception of the Rigdon Farm plots in 2002 and 2003, where 80 lateral branches were sampled systematically across plots of eight genotypes. Assessments began at 74 DAP in 2002 and between 55 and 59 DAP in 2003 and 2004. Leaf spot severity per plot was assessed using the Florida 1-to-10-scale rating system, where $1=$ no leaf spot; 2 = very few lesions on the leaves, none on the upper canopy; 3 = few lesions on the leaves, very few on the upper canopy; $4=$ some lesions with more on the upper canopy, $5 \%$ defoliation; 5 = lesions noticeable even on upper canopy, $20 \%$ defoliation; $6=$ lesions numerous and very evident on upper canopy, $50 \%$ defoliation; $7=$ lesions numerous on upper canopy, 75\% defoliation; $8=$ upper canopy covered with lesions, $90 \%$ defoliation; 9 = very few leaves remaining and those covered with lesions, 98\% defoliation; and $10=$ plants completely defoliated and killed by leaf spot (8). Severity assessments were made at 7 - to 22-day intervals five times beginning 89 DAP in 2002, nine times beginning 59 to 63 DAP in 2003, and six times beginning 56 DAP in 2004

Disease incidence and severity data were analyzed separately for each assessment technique. For each plot, area under the disease progress curve (AUDPC) was computed (18). For each plot, disease assessments were converted to proportions $(\mathrm{y}=$ percent incidence/100; $y=$ [Florida rating -1$] / 9)$, transformed using the linearizing transformation for the Gompertz $(-\ln [-\ln y])$, logistic $(\ln [y /(1-y)])$ and monomolecular $(\ln [1 /(1-y)])$ models, and linearly regressed on time (DAP), with DAP $=30$ set as the beginning of the epidemic, using SAS Proc REG (SAS version 8.3; SAS Institute, Cary, NC). Residual plots and recalculated $R^{2}$ values after back transformation were examined to select the model with the best fit (6). If none of the models fit a majority of the curves satisfactorily, the data were excluded from analyses. The model rate parameter ( $r$ ) was used as an estimate of the epidemic rate (6). Based on model-fitting results, a logistic model was selected as most appropriate for the majority of early leaf spot epidemics. Therefore, initial disease $\left(\mathrm{y}_{0}\right)$ was estimated as $\left(\mathrm{y}_{0}=\mathrm{e}^{\mathrm{y} \text { intercept }} /\left[1+\left(\mathrm{e}^{\mathrm{y} \text { intercept }}\right)\right]\right)$, and the time delay due to sanitation $\left(t_{s}\right)$ of strip tillage was calculated for each experiment separately and all experiments combined as $\left(\mathrm{t}_{\mathrm{s}}=1 / \mathrm{r} *\left[\ln \left(\mathrm{y}_{0 \mathrm{c}} /[1-\right.\right.\right.$ $\left.\left.\left.\left.\mathrm{y}_{0 \mathrm{c}}\right]\right)\right]-\left[\ln \left(\mathrm{y}_{0 \mathrm{~s}} /\left[1-\mathrm{y}_{0 \mathrm{~s}}\right]\right)\right]\right)$, where $\mathrm{r}^{*}$ is the mean $\mathrm{r}$, $\mathrm{y}_{0 \mathrm{c}}$ is the conventional tillage $\mathrm{y}_{0}$, and $\mathrm{y}_{0 \mathrm{~s}}$ is the strip tillage $\mathrm{y}_{0}(6)$. Effects of tillage on AUDPC, $\mathrm{y}_{0}$, and $\mathrm{r}$ were determined for each experiment separately and all experiments combined using the Proc MIXED procedure. Combined analyses were deemed acceptable because the model was standard for all plots.

Environmental monitoring. In all plots at the Rigdon Farm, air temperature (AT) and relative humidity $(\mathrm{RH})$ were measured every $30 \mathrm{~min}$ at the top of the peanut canopy each year, and within the canopy in 2003 and 2004 using HOBO dataloggers (H8 Pro Series; Onset Computer Corporation, Bourne, MA). Dataloggers also were used to measure soil temperature (ST) every $30 \mathrm{~min}$ at $5 \mathrm{~cm}$ below the soil surface. Environmental variables were monitored from 29 May to 15 September 2002, 16 June to 14 September 2003, and 17 June to 15 September 2004. Every 30-min reading was classified as favorable for infection if $\mathrm{RH} \geq 95 \%$ and AT $\geq 19^{\circ} \mathrm{C}$, and unfavorable otherwise, based on a previous study by Alderman et al. (2). Likewise, every 30-min reading was classified as favorable for spore dispersal if $\mathrm{RH} \geq 90 \%$ and $20 \leq$ $\mathrm{AT} \leq 24^{\circ} \mathrm{C}$, and unfavorable otherwise (2). Effects of tillage on environmental variables were determined by year to reduce model complexity for timely analysis of the large data set using the Proc MIXED procedure of SAS (the Satterthwaite option specified for calculation of degrees of freedom) with replication, replication-tillage, and replication-tillage within date as random effects. Effects of tillage on the frequencies of environmental assessment periods that were favorable for infection (infectionfavorable periods) or spore dispersal (dispersal-favorable periods) were evaluated separately based on a $\chi^{2}$ analysis (SAS Proc FREQ).

Monitoring initial infections and secondary inoculum. Asymptomatic leaves (trap leaves) were collected from plots at the Rigdon and Blackshank Farms in 2003 and 2004 to estimate the occurrence and frequency of primary infections using a method modified from Melouk et al. (14) and Waliyar et al. (22). Five first or second newly expanded leaves per plot were detached arbitrarily from lateral branches in conventionally tilled and striptilled plots. Cut ends of the petioles were dipped immediately in a dry formulation of napthaleneacetamide and thiram (Rootone; Security Products Co., Atlanta, GA) and set in sterile saturated sand in 100-ml beakers or test tubes filled with sterile water covered with Parafilm. Leaves were transported to the laboratory and incubated in a mist chamber at room temperature (20 to $23^{\circ} \mathrm{C}$ ) and a 12-h photoperiod. After $48 \mathrm{~h}$, misting was discontinued. Water was added to beakers and test tubes as needed. The mean number of lesions per leaf and percentage of leaves with lesions (incidence) were recorded after 2 weeks. Trap leaves were collected weekly, beginning 47 DAP in 2003 and 36 DAP in 2004, until disease was observed on at least one trap leaf from all plots. Tillage effects on the mean number of lesions per leaf and percent incidence from the final collection date for each field (47 DAP at the Blackshank Farm and 73 DAP at the Rigdon Farm in 2003, and 57 DAP at both Farms in 2004) were determined using the Proc MIXED procedure of SAS with year and field within year as random effects.

The density of $C$. arachidicola conidia per cubic meter of air was estimated for conventionally tilled and strip-tilled plots using Rotorod samplers (Model 20; Multidata, Inc., Minnetonka, MN). Samplers were placed $15 \mathrm{~cm}$ above the peanut canopy at the 
center of replicated plots and air was sampled from 11:00 a.m. to 1:00 p.m., based on a report by Alderman et al. (2) that secondary spore dispersal of $C$. arachidicola at $42 \mathrm{~cm}$ above the soil surface was greatest near noon. Air was sampled at the Rigdon Farm seven times between 58 and 101 DAP for one replication in 2002, nine times between 49 and 106 DAP for one to three replications in 2003, and between 85 and 92 DAP for two replications in 2004. Rods were incubated at room temperature $\left(20\right.$ to $\left.23^{\circ} \mathrm{C}\right)$ in a moist chamber for 24 to $48 \mathrm{~h}$. Incubation promoted germination of conidia to help distinguish conidia from similarly shaped debris or conidia of Fusarium sp., which tended to have longer germ tubes than $C$. arachidicola. After incubation, the rods were stained with cotton blue in lactophenol and covered with a 22-mm-long cover slip. Conidia of $C$. arachidicola were counted using a light microscope at $\times 400$ magnification. Spore densities were analyzed across sampling time with the Proc MIXED procedure with year and replication within year as random effects. Linear regression analysis was conducted across replications to determine the quantitative relationship between the tillage ratio (strip till/conventional till) of spore concentrations in the air (TRS) on the tillage ratio of disease severity (TRD) and incidence (TRI) in the same plots during the same week. Common dates for Rotorod sampling and disease incidence assessments were 73, 80, 87, 94, and 101 DAP in 2002; 65, 71, 88, and 91 DAP in 2003; and 92 DAP in 2004. Common dates for Rotorod sampling and disease severity assessments were 87 and 101 DAP in 2002; 65, 71, 88, 91, 101, and 106 DAP in 2003; and 92 DAP in 2004.

Host susceptibility assessment. Host susceptibility to infection by $C$. arachidicola conidia was monitored for leaves from conventionally tilled and strip-tilled plots at the Rigdon Farm in 2003 and Rigdon and Blackshank Farms in 2004 using the detached-leaf method described above. Ten first or second fully expanded leaves per plot were collected arbitrarily from lateral branches after plants were flowering and before evidence of disease in the fields, 42 DAP in 2003 and 29 DAP in 2004. Five leaves per plot were inoculated with conidia of $C$. arachidicola and five leaves were used as controls.

Conidia for inoculations were acquired from monoconidial cultures of $C$. arachidicola obtained the previous growing season using a technique modified from $\mathrm{Lu}$ et al. (13). Sporulating early leaf spot lesions were excised from leaves of 'Georgia Green' and swiped across water agar. After $24 \mathrm{~h}$ at room temperature, single germinated conidia were transferred to potato dextrose agar (PDA). Fungal colonies grown for 4 to 8 months $(0.5$ to $1.0 \mathrm{~cm}$ in diameter) were macerated in $1 \mathrm{ml}$ of sterile $0.005 \%$ Tween 20 using a homogenizer (TissueMiser; Fisher Scientific, Pittsburgh, PA). Aliquots of the homogenate $(0.25 \mathrm{ml})$ were spread evenly across clarified V8 juice agar plates with a glass rod. Plates were left without Parafilm until the medium was nearly dry, then wrapped with Parafilm and incubated under continuous light at room temperature $\left(20\right.$ to $23^{\circ} \mathrm{C}$ ) for 7 to 14 days. Conidia were rinsed from cultures with $10 \mathrm{ml}$ of $0.0005 \%$ Tween 20 . Spore concentrations were adjusted to 5,000 conidia $\mathrm{ml}^{-1}$ using a hemacytometer.

Leaves were sprayed uniformly for $1 \mathrm{~s}$ with the conidial suspension or with $0.005 \%$ Tween 20 as a control using an aerosol spray bottle. Leaves were positioned randomly on trays and placed in a transparent enclosure $(1.3$ by 0.7 by $0.6 \mathrm{~m})$ in a growth chamber set at $24^{\circ} \mathrm{C}, 90 \% \mathrm{RH}$, and a 12 -h photoperiod. The enclosure was constructed using 2.54-cm PVC pipe with clear plastic sides and a glass top. The enclosure did not affect AT. RH was supplemented by maintaining standing water in trays and with two humidifiers (PersonalMist ultrasonic humidifier; Kaz, Inc, Hudson, NY) evenly spaced within the enclosure. Humidifiers were programmed to operate continuously for the first $48 \mathrm{~h}$, then to turn off and on for alternating 30-min periods while the lights were on and to turn off with the lights, to maintain continuous leaf wetness without runoff. Water was added to beakers and trays as needed.
After 28 days, the number of lesions per leaf, lesion diameter, percentage of lesions with sporulation, and number of leaflets defoliated were recorded. The Proc MIXED procedure was used to determine effects of tillage on nontransformed and square-roottransformed response variables listed above.

\section{RESULTS}

Disease progress curves of early leaf spot incidence in conventionally tilled and strip-tilled plots at each field and year are shown in Figure 1. The increase in disease incidence over time was best described by the logistic model for each plot at the Rigdon Farm each year (2002, $P<0.01$, recalculated $R^{2} \geq 0.82$; $2003, P<0.01$, recalculated $R^{2} \geq 0.63 ; 2004, P \leq 0.05$, recalculated $\left.R^{2} \geq 0.67\right)$, and at the Blackshank Farm in $2004(P \leq$ 0.04 , recalculated $R^{2} \geq 0.52$ ). No model satisfactorily described the increase in disease incidence over time at the Blackshank Farm in $2003(P \geq 0.14)$. Disease progress curves of Florida scale severity ratings in conventionally tilled and strip-tilled plots in each field and year are shown in Figure 2. The logistic model best described the increase in disease severity over time for plots in each field and year (Rigdon Farm: 2002, $P<0.01$, recalculated $R^{2} \geq 0.72 ; 2003, P<0.01$, recalculated $R^{2} \geq 0.86 ; 2004, P<0.01$, recalculated $R^{2} \geq 0.92$; and Blackshank Farm: 2003, $P<0.01$, recalculated $R^{2} \geq 0.92$; and 2004, $P<0.01$, recalculated $R^{2} \geq$ 0.94).

Early leaf spot epidemics, as measured by AUDPC based on incidence and severity, were less severe in strip-tilled than conventionally tilled plots (Table 1). Estimates of $\mathrm{y}_{0}$ were significantly lower in strip-tilled plots than conventionally tilled plots for one of four experiments based on incidence models and two of five experiments based on severity models. When experiments were combined, estimated $\mathrm{y}_{0}$ was significantly lower in strip-tilled plots than conventionally tilled plots for both incidence and severity (Table 1). Estimates of $r$ were comparable among all experiments based on models of disease incidence (Table 1). Based on models of disease severity, $r$ was comparable across the tillage treatments in three experiments, significantly greater in the strip-tillage plots for one experiment, and significantly less in the strip-tillage plots for one experiment (Table 1). Strip-tillage $t_{s}$ based on incidence and severity models was -4.1 and 3.6 days at the Rigdon Farm in 2002, 7.4 and 17.1 days at the Rigdon Farm in 2003, 12.6 and 4.8 days at the Rigdon Farm in 2004, and 7.1 and 12.4 days at the Blackshank Farm in 2004, respectively. At the Blackshank farm in 2003, strip-tillage $t_{s}$ based on severity was 20.5 days.

Tillage treatments did not affect mean air temperatures measured at the top of the peanut canopy $(P \geq 0.48)$ or within the canopy $(P \geq 0.53)$, or mean soil temperatures $(P \geq 0.14)$ (Table 2$)$. In 2002, the mean RH at the top of the canopy was lower in striptilled plots than conventionally tilled plots by nearly $2 \%(P<$ $0.01)$, but no effect on mean RH was observed in 2003 or 2004 $(P \geq 0.49)$ (Table 2).

In 2002, infection- and dispersal-favorable periods were significantly fewer in strip-tilled plots than conventionally tilled plots at the top of the peanut canopy (Table 3). Differences were not detected between tillage treatments in 2003 or 2004, with the exception of fewer dispersal-favorable periods for strip-tilled plots within the canopy than conventionally tilled plots in 2003 .

Estimates of initial infections and secondary inoculum densities in the air differed between tillage treatments. Random effects, year, and field within year, were not significant; therefore, data were pooled across fields and years. The mean number of initial infections per trap leaf and the percentage of trap leaves with infections were lower in strip-tilled plots than conventionally tilled plots $(P<0.01)$ (Table 4$)$. The mean concentration of spores in the air above strip-tilled plots was lower than that above conventionally tilled plots $(P<0.01)$ (Table 4$)$. Across years, the tillage 
ratio (strip till/conventional till) of spore concentration in the air (TRS) was positively correlated to the tillage ratio of disease severity $(\mathrm{TRD})\left(P=0.02\right.$; TRS $\left.=0.15 \mathrm{TRD}+0.61, R^{2}=0.57\right)$, but was not correlated to the ratio of disease incidence $(P=0.49)$.

No measure of host susceptibility was affected by tillage $(P>$ 0.35 ). The overall means of inoculated leaves combined over tillage treatments were 36.3 lesions per leaf, 1.5 -mm lesion diameter, $35 \%$ lesions with sporulation, and $33 \%$ leaflets defoliated. No lesions developed on the control leaves.

\section{DISCUSSION}

Results of our 3-year field study provide evidence that the primary manner of early leaf spot suppression by strip tillage is to reduce the amount of initial infections, which results in a delay of the epidemic. The mean time savings due to strip tillage was 5.7 and 11.7 days, which suggests that timing of the initial fungicide spray for management of early leaf spot may be delayed by a week or more in strip-tilled fields without a detrimental effect on disease management.
Both disease assessment techniques (incidence and severity) were useful to demonstrate early leaf spot suppression by strip tillage. Neither technique was better or more consistent for detecting differences of $y_{0}$ and $r$ by tillage treatment. Estimates of $y_{0}$ varied among experiments, which was not unexpected due to the reliance on natural sources of inocula. Although estimates of $\mathrm{y}_{0}$ were not always significantly lower in the strip-tilled plots than the conventionally tilled plots, there was a numerical trend toward this direction in most cases and, in analyses of combined data from all experiments, $\mathrm{y}_{0}$ differed significantly between tillage treatments for both incidence and severity assessments. An exception to this trend occurred in 2002, where the estimated time savings due to strip tillage was -4.1 days based on incidence models and 3.6 days based on severity models. The epidemic began later in 2002 than it did in the other experiments, and it is possible that the standardized disease onset date of 30 DAP for all experiments may have resulted in a poor estimation of $\mathrm{y}_{0}$ for both treatment plots that year. Examination of disease progress curves suggests that there was a comparable delay to the epidemic in the striptillage plots compared with the conventionally tilled plots in 2002
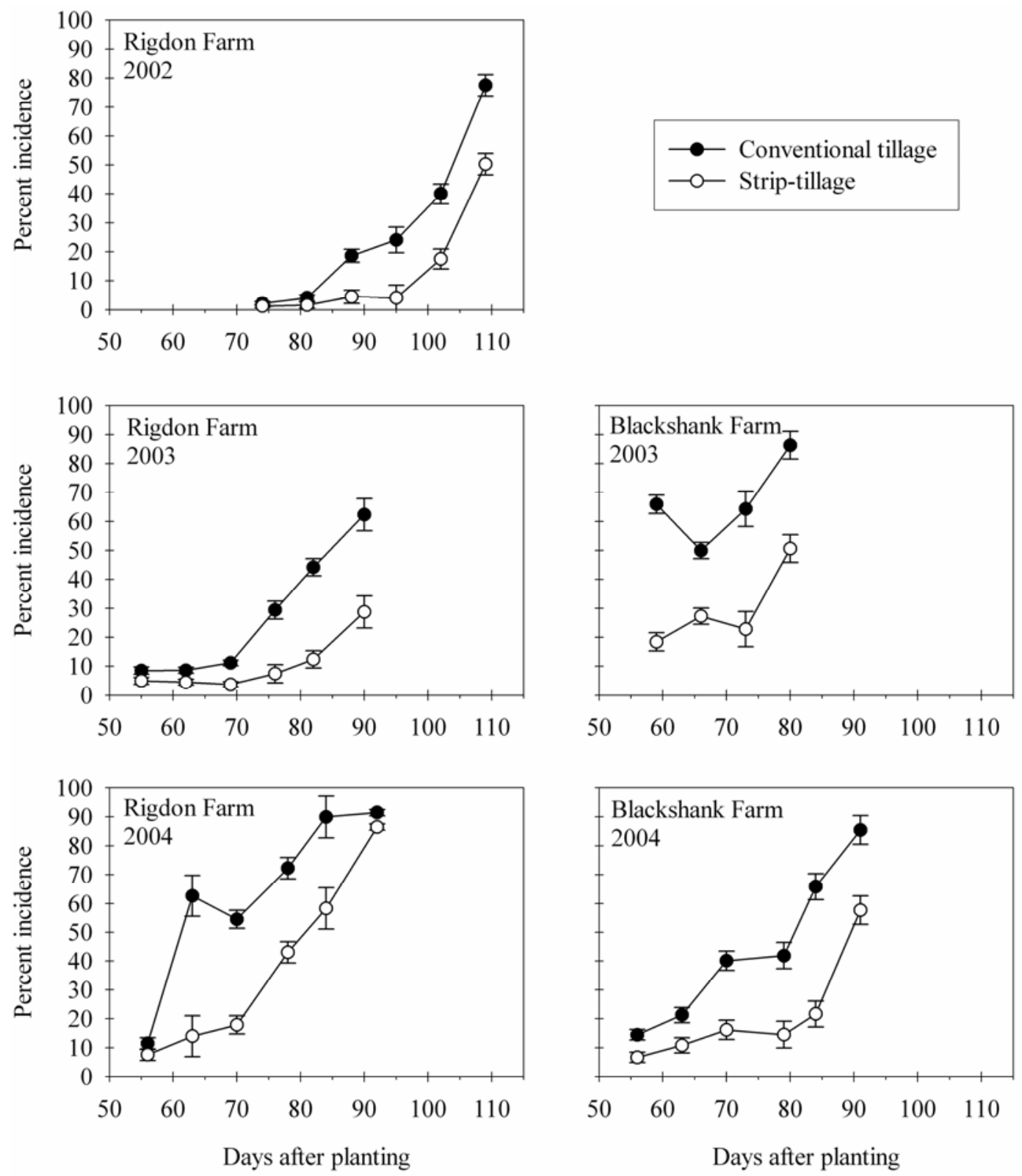

Fig. 1. Progress of early leaf spot incidence over time for peanut plots in conventionally tilled and strip-tilled plots at two locations in 2002 to 2004 . Treatment means of three or four replications and standard error bars are shown for each assessment date. 
as occurred in the other experiments. The mean time savings due to strip tillage increased to 8.9 days based on incidence and 13.7 days based on severity when 2002 data was excluded.

Although, in some cases, the apparent infection rate was lower in strip tillage than conventional tillage, these differences were less consistent and of smaller magnitude compared with differences in $\mathrm{y}_{0}$. In modeling, it is often assumed that dispersal of initial inocula from an overwintering source occurs as a single event; however, it is likely that additional inoculum from the soil contributes to early leaf spot epidemics after initiation of secondary spread. This may explain why the apparent infection rate appeared to be a more important factor by estimates of incidence, which more accurately measures early epidemic development, than severity, which is a better measure of the mid-to late portion of the epidemic.

The logistic model fit most temporal disease progress curves relatively well, with the exception of the early leaf spot incidence curves at the Blackshank Farm in 2003, which was excluded from rate and $\mathrm{y}_{0}$ analyses. In this experiment, disease onset occurred earlier and with greater intensity than it did in other years and locations. Digression of the curves shortly after onset was most likely due to a faster rate of host growth than disease progression between the initial assessment (59 DAP) and the assessment that followed 1 week later. This is supported by the high incidence and frequency of early leaf spot symptoms observed on asymptomatic detached trap leaves collected in the conventionally tilled plots at 47 DAP, even though early leaf spot symptoms were not evident in the field at the time of collection.

The fewer initial infections observed in strip-tilled plots compared with conventionally tilled plots most likely are due to fewer or less viable conidia of $C$. arachidicola dispersed to peanut leaves from overwintering stroma in the soil. When detached trap leaves were incubated in a controlled environment, early infection was significantly lower in leaves from strip-tilled plots than conventionally tilled plots. In contrast, components of host resistance of inoculated detached leaves did not differ between the tillage systems. Our inability to detect a host resistance response to tillage is circumstantial evidence that the tillage effect on early leaf spot
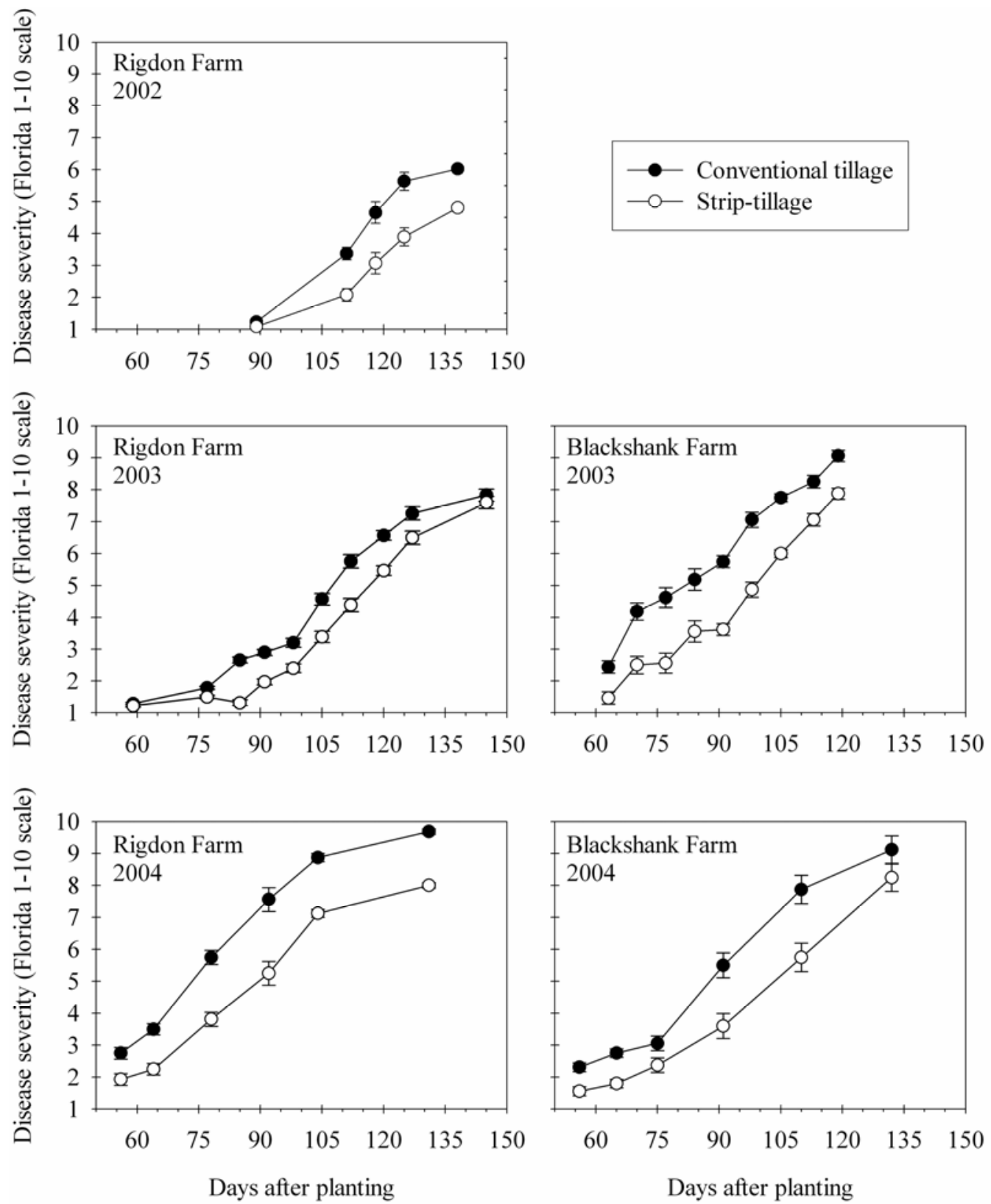

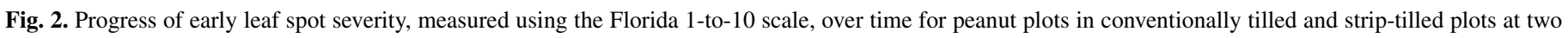
locations in 2002 to 2004 . Treatment means of three or four replications and standard error bars are shown for each assessment date. 


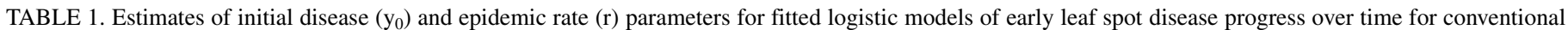
and strip tillage at the Rigdon and Blackshank Farms, 2002 to $2004^{\mathrm{x}}$

\begin{tabular}{|c|c|c|c|c|c|c|}
\hline \multirow[b]{2}{*}{ Year, farm, treatment } & \multicolumn{3}{|c|}{ Incidence ${ }^{y}$} & \multicolumn{3}{|c|}{ Severity $^{\mathrm{z}}$} \\
\hline & $\mathrm{y}_{0}$ & $\mathrm{r}$ & AUDPC & $\mathrm{y}_{0}$ & $\mathrm{r}$ & AUDPC \\
\hline \multicolumn{7}{|l|}{ 2002, Rigdon Farm } \\
\hline Conventional tillage & $2.6 \times 10^{-6}$ & 0.179 & 886 & $4.1 \times 10^{-4}$ & 0.081 & 525 \\
\hline Strip tillage & $5.0 \times 10^{-6}$ & 0.158 & 395 & $3.1 \times 10^{-4}$ & 0.076 & 366 \\
\hline$P$ value & 0.96 & 0.22 & $<0.01$ & 0.58 & 0.22 & $<0.01$ \\
\hline \multicolumn{7}{|l|}{ 2003, Rigdon Farm } \\
\hline Conventional tillage & $3.1 \times 10^{-3}$ & 0.104 & 918 & $6.9 \times 10^{-3}$ & 0.059 & 625 \\
\hline Strip tillage & $1.6 \times 10^{-3}$ & 0.087 & 324 & $2.4 \times 10^{-3}$ & 0.064 & 510 \\
\hline$P$ value & 0.23 & 0.07 & $<0.01$ & $<0.01$ & 0.03 & $<0.01$ \\
\hline \multicolumn{7}{|l|}{ 2003, Blackshank Farm } \\
\hline Conventional tillage & $\ldots$ & $\ldots$ & 1,333 & $3.5 \times 10^{-2}$ & 0.060 & 330 \\
\hline Strip tillage & $\ldots$ & $\ldots$ & 592 & $9.5 \times 10^{-3}$ & 0.069 & 243 \\
\hline$P$ value & $\ldots$ & $\ldots$ & $<0.01$ & 0.02 & 0.17 & $<0.01$ \\
\hline \multicolumn{7}{|l|}{ 2004, Rigdon Farm } \\
\hline Conventional tillage & $1.6 \times 10^{-2}$ & 0.112 & 2,388 & $4.7 \times 10^{-2}$ & 0.065 & 532 \\
\hline Strip tillage & $3.7 \times 10^{-3}$ & 0.122 & 1,335 & $3.7 \times 10^{-2}$ & 0.049 & 401 \\
\hline$P$ value & 0.02 & 0.33 & $<0.01$ & 0.41 & 0.02 & $<0.01$ \\
\hline \multicolumn{7}{|l|}{ 2004, Blackshank Farm } \\
\hline Conventional tillage & $1.3 \times 10^{-2}$ & 0.096 & 1,508 & $3.2 \times 10^{-2}$ & 0.058 & 434 \\
\hline Strip tillage & $7.5 \times 10^{-3}$ & 0.077 & 662 & $1.6 \times 10^{-2}$ & 0.056 & 328 \\
\hline$P$ value & 0.37 & 0.13 & $<0.01$ & 0.11 & 0.80 & 0.02 \\
\hline \multicolumn{7}{|c|}{ All years, locations combined } \\
\hline Conventional tillage & $7.1 \times 10^{-3}$ & 0.126 & 1,309 & $2.3 \times 10^{-2}$ & 0.067 & 496 \\
\hline Strip tillage & $1.5 \times 10^{-3}$ & 0.116 & 699 & $1.1 \times 10^{-2}$ & 0.065 & 365 \\
\hline$P$ value & 0.02 & 0.09 & $<0.01$ & $<0.01$ & 0.47 & $<0.01$ \\
\hline
\end{tabular}

${ }^{x}$ Least square means from Proc MIXED analysis. AUDPC $=$ area under the disease progress curve.

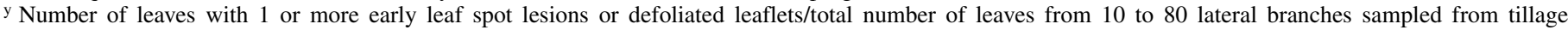
plots.

${ }^{\mathrm{z}}$ Based on Florida 1-to-10 scale ratings.

TABLE 2. Effects of tillage treatments on air and soil temperatures and relative humidity (RH) in peanut plots, 2002 to $2004^{t}$

\begin{tabular}{|c|c|c|c|c|c|c|c|c|c|c|c|c|c|c|c|}
\hline \multirow[b]{3}{*}{ Year, till ${ }^{\mathrm{w}}$} & \multicolumn{6}{|c|}{ Top of canopy ${ }^{u}$} & \multicolumn{6}{|c|}{ Within canopy ${ }^{\mathrm{v}}$} & \multirow{2}{*}{\multicolumn{3}{|c|}{$\frac{\text { Soil }(5 \text {-cm depth) }}{\text { Temperature }\left({ }^{\circ} \mathrm{C}\right)}$}} \\
\hline & \multicolumn{3}{|c|}{ Temperature $\left({ }^{\circ} \mathrm{C}\right)$} & \multicolumn{3}{|c|}{$\mathrm{RH}(\%)$} & \multicolumn{3}{|c|}{ Temperature $\left({ }^{\circ} \mathrm{C}\right)$} & \multicolumn{3}{|c|}{$\mathrm{RH}(\%)$} & & & \\
\hline & Mean & Min & $\operatorname{Max}$ & Mean & Min & Max & Mean & Min & $\operatorname{Max}$ & Mean & Min & Max & Mean & Min & $\operatorname{Max}$ \\
\hline \multicolumn{16}{|l|}{$2002^{x}$} \\
\hline Conv & $26.3 \mathrm{a}$ & 14.3 & 44.0 & $86.0 \mathrm{~b}$ & 19.1 & 100 & $\ldots$ & $\ldots$ & $\ldots$ & $\ldots$ & $\ldots$ & $\ldots$ & $27.1 \mathrm{a}$ & 20.5 & 40.2 \\
\hline Strip & $26.4 \mathrm{a}$ & 14.2 & 43.8 & $84.0 \mathrm{a}$ & 17.9 & 100 & $\ldots$ & $\ldots$ & $\ldots$ & $\ldots$ & $\ldots$ & $\ldots$ & $27.3 \mathrm{a}$ & 20.9 & 43.1 \\
\hline$F$ & 0.51 & $\ldots$ & $\ldots$ & 6.88 & $\ldots$ & $\ldots$ & $\ldots$ & $\ldots$ & $\ldots$ & $\ldots$ & $\ldots$ & $\ldots$ & 2.14 & $\ldots$ & $\ldots$ \\
\hline $\begin{array}{c}\text { df } \\
2003 y\end{array}$ & 562 & $\ldots$ & $\ldots$ & 573 & $\ldots$ & $\ldots$ & $\ldots$ & $\ldots$ & $\ldots$ & $\ldots$ & $\ldots$ & $\ldots$ & 613 & $\ldots$ & $\ldots$ \\
\hline Conv & $25.5 \mathrm{a}$ & 13.9 & 39.1 & $89.4 \mathrm{a}$ & 37.1 & 100 & $25.9 \mathrm{a}$ & 14.4 & 42.9 & $93.9 \mathrm{a}$ & 34.7 & 100 & $26.6 \mathrm{a}$ & 16.9 & 40.7 \\
\hline Strip & $25.5 \mathrm{a}$ & 14.0 & 38.5 & $90.0 \mathrm{a}$ & 36.3 & 100 & $25.7 \mathrm{a}$ & 15.2 & 38.9 & $93.6 \mathrm{a}$ & 37.2 & 100 & $26.7 \mathrm{a}$ & 20.0 & 38.4 \\
\hline$F$ & 0.00 & $\ldots$ & $\ldots$ & 0.74 & $\ldots$ & $\ldots$ & 0.51 & $\ldots$ & $\ldots$ & 0.05 & $\ldots$ & $\ldots$ & 0.14 & $\ldots$ & $\ldots$ \\
\hline df & 460 & $\ldots$ & $\ldots$ & 1.8 & $\ldots$ & $\ldots$ & 2.7 & $\ldots$ & $\ldots$ & 1.6 & $\ldots$ & $\ldots$ & 1.7 & $\ldots$ & $\ldots$ \\
\hline $2004^{z}$ & & & & & & & & & & & & & & & \\
\hline Conv & $26.0 \mathrm{a}$ & 17.4 & 40.9 & $90.3 \mathrm{a}$ & 30.9 & 100 & $26.1 \mathrm{a}$ & 18.0 & 40.3 & $93.4 \mathrm{a}$ & 37.1 & 100 & $26.7 \mathrm{a}$ & 22.6 & 39.0 \\
\hline Strip & $25.9 \mathrm{a}$ & 17.1 & 39.1 & $90.5 \mathrm{a}$ & 32.8 & 100 & $26.0 \mathrm{a}$ & 18.2 & 39.8 & $93.3 \mathrm{a}$ & 38.3 & 100 & $26.8 \mathrm{a}$ & 22.5 & 37.8 \\
\hline$F$ & 0.04 & $\ldots$ & $\ldots$ & 0.07 & $\ldots$ & $\ldots$ & 0.25 & $\ldots$ & $\ldots$ & 0.04 & $\ldots$ & $\ldots$ & 1.22 & $\ldots$ & $\ldots$ \\
\hline df & 633 & $\ldots$ & $\ldots$ & 6.1 & $\ldots$ & $\ldots$ & 5.5 & $\ldots$ & $\ldots$ & 6.3 & $\ldots$ & $\ldots$ & 4.6 & $\ldots$ & $\ldots$ \\
\hline
\end{tabular}

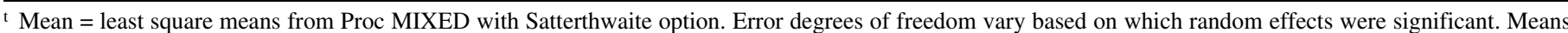
within a column for the same year with the same letter do not differ at the 5\% level.

"Hobo data logger sensors placed within the top $1 \mathrm{~cm}$ of the peanut canopy.

${ }^{v}$ Hobo data logger sensors were 2 to $5 \mathrm{~cm}$ above the soil surface within the peanut canopy.

${ }^{\mathrm{w}}$ Till $=$ tillage treatments: Conv $=$ conventionally tilled plots and Strip $=$ strip-tilled plots.

${ }^{x}$ Three sensors per tillage treatment recorded variables every $30 \mathrm{~min}$ from 29 May to 15 September.

y Three sensors per tillage treatment recorded every $30 \mathrm{~min}$ from 16 June to 14 September.

${ }^{\mathrm{z}}$ Four sensors per tillage treatment recorded every $30 \mathrm{~min}$ from 17 June to 15 September.

epidemics is not associated with a chemical or biotic difference on the phylloplane, induction of resistance to $C$. arachidicola, or predisposition to infection in conventionally tilled peanut.

Environmental variables measured in this study did not consistently differ between tillage treatments across years. However, differences in the epidemics of the two tillage treatments were observed in all years. It is important to point out that strip tillage and cover crop residue do not appear to enhance $\mathrm{RH}$ around peanut plants, which was previously assumed (11).
Although the detached trap leaf method did not provide a direct measure of initial inoculum, similar methods that employ trap plants are standard procedures used to estimate early season inoculum levels of foliar pathogens within a uniform environment (6). In this study, detached trap leaves were preferable to container trap plants because they provided a more natural setting for spore capture, and allowed for investigation of larger sample sizes because space in the mist chamber was limited. Rotorod samplers were not useful to monitor initial inoculum densities because no 
TABLE 3. Effect of tillage on the frequency of environmental records favorable for infection or spore dispersal in peanut plots, 2002 to $2004^{t}$

\begin{tabular}{|c|c|c|c|c|c|c|}
\hline \multirow[b]{2}{*}{ Year, tillage $^{\mathrm{w}}$} & \multicolumn{3}{|c|}{ Top of canopy ${ }^{\mathrm{u}}$} & \multicolumn{3}{|c|}{ Within canopy ${ }^{\mathrm{V}}$} \\
\hline & Number $(\mathrm{N})^{\mathrm{x}}$ & Infection, $\mathrm{n}(\%)^{\mathrm{y}}$ & Dispersal, $\mathrm{n}(\%)^{\mathrm{z}}$ & Number $(\mathrm{N})^{\mathrm{x}}$ & Infection, $\mathrm{n}(\%)^{\mathrm{y}}$ & Dispersal, $\mathrm{n}(\%)^{\mathrm{z}}$ \\
\hline \multicolumn{7}{|l|}{2002} \\
\hline Conv & 14,645 & $7,058(48.2) \mathrm{b}$ & $5,688(38.8) b$ & $\ldots$ & $\ldots$ & $\ldots$ \\
\hline Strip & 12,317 & 5,285 (42.9) a & $4,467(36.3) \mathrm{a}$ & $\ldots$ & $\ldots$ & $\ldots$ \\
\hline \multicolumn{7}{|l|}{2003} \\
\hline Conv & 9,062 & $4,667(51.5) \mathrm{a}$ & $3,994(44.1) \mathrm{a}$ & 12,873 & $8,346(64.8) b$ & $5,176(40.2) \mathrm{a}$ \\
\hline Strip & 13,593 & $7,178(52.8) \mathrm{a}$ & 5,965 (43.9) a & 10,740 & $6,802(63.3) \mathrm{a}$ & $4,271(39.8) \mathrm{a}$ \\
\hline \multicolumn{7}{|l|}{2004} \\
\hline Conv & 15,630 & $8,802(56.3) \mathrm{a}$ & $7,035(45.0) \mathrm{a}$ & 17,268 & 10,692 (61.9) a & $7,284(42.2) \mathrm{a}$ \\
\hline Strip & 14,044 & $7,885(56.1) \mathrm{a}$ & $6,211(44.2) \mathrm{a}$ & 14,635 & $9,054(61.9) \mathrm{a}$ & 6,135 (41.9) a \\
\hline
\end{tabular}

${ }_{\mathrm{t}}$ Values in each column within a year followed by the same letter do not differ significantly, based on $\chi^{2}$ test, 1 degree of freedom, $5 \%$ critical value is 3.84 .

u Hobo data logger sensors placed within the top $2 \mathrm{~cm}$ of peanut canopy.

v Sensors placed at least $2 \mathrm{~cm}$ above soil surface within peanut canopy.

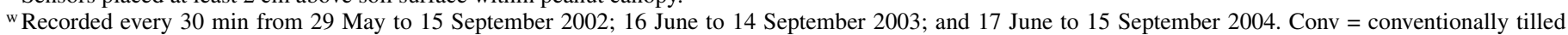
plots and Strip $=$ strip-tilled plots.

$x$ Total number of 30-min records of air temperature (AT) and relative humidity (RH) used per year.

${ }^{\mathrm{y}}$ Frequency favorable for infection, $\mathrm{RH} \geq 95 \%$ and $\mathrm{AT} \geq 19^{\circ} \mathrm{C}$ as reported by Alderman et al. (2).

${ }^{\mathrm{z}}$ Frequency favorable for spore dispersal, $\mathrm{RH} \geq 90 \%$ and $20 \leq \mathrm{AT} \leq 24^{\circ} \mathrm{C}$ as reported by Alderman et al. (2).

TABLE 4. Effect of tillage on initial early leaf spot infections, 2003 to 2004, and concentration of Cercospora arachidicola conidia in air above peanut plots, 2002 to $2004^{t}$

\begin{tabular}{lcccc}
\hline & \multicolumn{2}{c}{ Initial infections $^{\mathrm{u}}$} & & Secondary inoculum $^{\mathrm{v}}$ \\
\cline { 2 - 3 } \cline { 5 - 5 } Tillage $^{\mathrm{w}}$ & Lesions $(\mathrm{n})^{\mathrm{x}}$ & Incidence $(\%)^{\mathrm{y}}$ & & Conc. $\left(\text { conidia } / \mathrm{m}^{3}\right)^{\mathrm{z}}$ \\
\hline Conv & $5.5 \mathrm{~b}$ & $64 \mathrm{~b}$ & $16.4 \mathrm{~b}$ \\
Strip & $0.4 \mathrm{a}$ & $28 \mathrm{a}$ & $9.8 \mathrm{a}$ \\
SE & 1.37 & 4.2 & & 1.0 \\
\hline
\end{tabular}

${ }^{t}$ Means within a column with the same letter do not differ at the $5 \%$ level.

u Monitored for five detached leaves per tillage plot 47 days after planting (DAP) at the Blackshank Farm and 73 DAP at the Rigdon Farm in 2003, and 57 DAP at both farms in 2004.

${ }^{v}$ Least square means across year and sample date from Proc MIXED of sampled air using Rotorod samplers $15 \mathrm{~cm}$ above the peanut canopy from 11:00 a.m. to 1:00 p.m.

${ }^{\mathrm{w}}$ Conv $=$ conventional, strip $=$ strip-tilled, and $\mathrm{SE}=$ standard error .

${ }^{x}$ Number of lesions per leaf.

y Percent incidence: number of leaves with one or more early leaf spot lesions/ total number of leaves $\times 100$.

${ }^{\mathrm{z}}$ Concentration per cubic meter of air.

conidia were detected with samplers prior to the observation of secondary inoculum on lesions within the peanut canopy. Rotorod samplers were useful for detecting differences in airborne inoculum densities; however, quantification of secondary inoculum concentrations in the air was time consuming and challenged by the capture of various structures with a similar color and shape to C. arachidicola conidia. Although airborne inoculum densities of C. arachidicola are highly affected by weather (2), the positive relationship between the tillage ratios (strip till/conventional till) of disease severity and airborne inoculum densities suggests that estimates of disease severity may be a reasonable indicator of the relative density potential of secondary inoculum in the air above plots. The lack of a correlation between the tillage ratio of airborne inoculum density and disease incidence likely was due to lower levels of disease for the incidence rating dates than severity dates, which may have led to insufficient numbers of spores sampled to detect tillage differences.

In conclusion, strip tillage delays epidemic development of early leaf spot by a week or more, which may enable growers to delay their first fungicide application in strip-tilled fields without detrimental affects on disease management. More research will be needed to support this hypothesis prior to changing recommendations to growers; however, delaying the initial spray by 7 to 10 days in strip-tilled fields may allow an additional fungicide savings on top of the two to three fewer fungicides that already have been documented based on extended interval research in strip tillage.

\section{ACKNOWLEDGMENTS}

This research was supported in part by the Georgia Peanut Commission and the National Peanut Board. We thank M. Heath, S. Gremillion, S. Carter, S. Bertrand, and A. McKeown for their field assistance; and B. G. Mullinix, Jr., for statistical advisement.

\section{LITERATURE CITED}

1. Agrios, G. N. 1997. Plant Pathology. 4th ed. Academic Press, San Diego, CA.

2. Alderman, S. C., Matyac, C. A., Bailey, J. E., and Beute, M. K. 1987. Aeromycology of Cercospora arachidicola on peanut. Trans. Br. Mycol. Soc. 89:97-103.

3. Aquino, V. M., Shokes, F. M., Gorbet, D. W., and Nutter, F. W., Jr. 1995. Late leaf spot progression on peanut as affected by components of partial resistance. Plant Dis. 79:74-78.

4. Bailey, K. L. 1996. Diseases under conservation tillage systems. Can. J. Plant Sci. 76:635-639.

5. Bockus, W. W., and Shroyer, J. P. 1998. The impact of reduced tillage on soilborne plant pathogens. Annu. Rev. Phytopathol. 36:485-500.

6. Campbell, C. L., and Madden, L. V. 1990. Introduction to Plant Disease Epidemiology. Wiley, New York.

7. Cantonwine, E. G., Culbreath, A. K., Stevenson, K. L., Kemerait, R. C., Jr., Brenneman, T. B., Smith, N. B., and Mullinix, B. G., Jr. 2006. Integrated disease management of leaf spot and spotted wilt of peanut. Plant Dis. 90:493-500.

8. Chiteka, Z. A., Gorbet, D. W., Shokes, F. M., Kucharek, T. A., and Knauft, D. A. 1988. Components of resistance to late leaf spot in peanut I. Levels of variability-implications for selection. Peanut Sci. 15:25-30.

9. Everts, K. L. 2002. Reduced fungicide applications and host resistance for managing three diseases in pumpkin grown on a no-till cover crop. Plant Dis. 86:1134-1141.

10. Johnson, C. S., Beute, M. K., and Ricker, M. D. 1986. Relationship between components of resistance and disease progress of early leaf spot on Virginia-type peanut. Phytopathology 76:495-499.

11. Johnson, W. C., III, Brenneman, T. B., Baker, S. H., Johnson, A. W., Sumner, D. R., and Mullinix, B. G., Jr. 2001. Tillage and pest management considerations in a peanut-cotton rotation in the southeastern coastal plain. Agron. J. 93:570-576.

12. Kranz, J. 2003. Comparative Epidemiology of Plant Diseases. Springer, Berlin, New York.

13. Lu, Y. J., Shew, B. B., and Ypema, H. L. 2003. In vitro sporulation of Cercospora arachidicola from peanut and sensitivity of spore germination to pyraclostrobin. (Abstr.) Phytopathology 93:S54.

14. Melouk, H. A., and Banks, D. J. 1978. A method of screening peanut genotypes for resistance to Cercospora leafspot. Peanut Sci. 5:112-114.

15. Miller, I. L., Norden, A. J., Knauft, D. A., and Gorbet, D. W. 1990. Influence of maturity and fruit yield on susceptibility of peanut to Cercosporidium personatum (late leafspot pathogen). Peanut Sci. 17:52-58.

16. Monfort, W. S., Culbreath, A. K., Stevenson, K. L., Brenneman, T. B., Gorbet, D. W., and Phatak, S. C. 2004. Effects of reduced tillage, resistant cultivars, and reduced fungicide inputs on progress of early leaf spot of peanut (Arachis hypogaea). Plant Dis. 88:858-864. 
17. Porter, D. M., and Wright, F. S. 1991. Early leaf spot of peanuts: Effect of conservational tillage practices on disease development. Peanut Sci. 18:76-79.

18. Shaner, G., and Finney, R. E. 1977. The effect of nitrogen fertilization on the expression of slow-mildewing resistance in Knox wheat. Phytopathology 67:1051-1056.

19. Shew, B. B., Beute, M. K., and Wynne, J. C. 1988. Effects of temperature and relative humidity on expression of resistance to Cercosporidium personatum in peanut. Phytopathology 78:493-498.

20. Shokes, F. M., and Culbreath, A. K. 1997. Early and late leaf spots. Pages
17-20 in: Compendium of Peanut Diseases, 2nd ed. N. Kokalis-Burelle, D. M. Porter, R. Rodriguez-Kabana, D. H. Smith, and P. Subrahmanyam, eds. The American Phytopathological Society, St. Paul, MN.

21. Smith, D. H., and Littrell, R. H. 1980. Management of peanut foliar diseases with fungicides. Plant Dis. 64:356-361.

22. Waliyar, F., Shew, B. B., Sidahmed, R., and Beute, M. K. 1995. Effects of host resistance on germination of Cercospora arachidicola on peanut leaf surfaces. Peanut Sci. 22:154-157.

23. Woodroof, N. C. 1933. Two leaf spots of the peanut (Arachis hypogaea L.). Phytopathology 23:627-640. 